\title{
Ramón de la Sota: La contribución de un empresario vasco a la modernización económica y política de la España de la Restauración
}

\author{
EUgENIO TORRES VILLANUEVA*
}

\section{O. PRESENTACIÓN}

El objeto de esta comunicación es dar a conocer de forma breve algunas de las principales conclusiones de mi tesis doctoral titulada Ramón de la Sota: Historia económica de un empresario (1857-1936), que defendí el pasado mes de mayo en el departamento que figura al comienzo de este escrito, y para cuya realización conté con la ayuda material del Banco de España y con la dirección del catedrático don Pedro Tedde de Lorca.

Dado el contenido y los fines del coloquio, dividiré la exposición en tres partes. Situaré en la primera a Ramón de la Sota en el contexto histórico en el que desenvolvió su actividad, para sintetizar después lo que puede considerarse como su aportación a la modernización económica (parte segunda) y política (parte tercera) de la España de la Restauración.

* Universidad Complutense. 


\section{UN MIEMBRO DESTACADO DE LA OLIGARQUIA VIZCAÍNA}

La biografía de Ramón de la Sota está circunscrita por dos fechas: 1857, año de su nacimiento en Castro Urdiales (Santander), y 1936, fecha de su fallecimiento en Guecho (Vizcaya) tan sólo un mes después del inicio de la Guerra Civil. No obstante, son los 55 años que van desde 1881 , en que comenzó su actividad empresarial, hasta su muerte los que tienen interés para nosotros, pues durante ellos puso en marcha y dirigió uno de los grupos empresariales españoles más poderosos: el grupo Sota y Aznar, con intereses en sectores productivos tan importantes como la minería del hierro, el transporte marítimo, la construcción naval, la de material ferroviario y eléctrico, la siderurgia, la metalurgia, los ferrocarriles, la hidroelectricidad, la banca, los seguros y hasta el sector inmobiliario.

Este licenciado en Derecho por la Universidad Central de Madrid, que presenció de cerca, mientras cursaba sus estudios, los dos acontecimientos políticos más trascendentales para el futuro de España y del País Vasco - la Restauración de la Monarquía borbónica y la abolición de los Fueros de las Provincias Vascongadas-, descendía de una familia de la nobleza rural de las Encartaciones vizcaínas con intereses en el comercio de la vena de Somorrostro y en el existente con las colonias americanas, y dueña, a su vez, de bienes raíces y caseríos de los que obtenía rentas. Junto a esta ascendencia, y sin olvidar su propia capacidad emprendedora, los dos elementos que completan el cuadro familiar de los orígenes de su actividad empresarial fueron su matrimonio con Catalina de Aburto, descendiente de una familia de comerciantes afincados en Bilbao, y, sobre todo, la alianza con su primo hermano Eduardo Aznar de la Sota, que desde 1881 sirvió para sentar las bases del grupo empresarial Sota y Aznar aprovechando las oportunidades que se crearon entonces en Vizcaya con la explotación en gran escala de sus yacimientos de mineral de hierro y con la aparición de su moderna industria siderúrgica.

Casi todas estas referencias son comunes a la mayoría de los miembros de lo que se ha dado en llamar "oligarquía vizcaína», el grupo social económicamente dominante y poíticamente hegemónico en Vizcaya durante la Restauración. En su haber no sólo hay que colocar el protagonismo de una parte sustancial del desarrollo industrial y de la modernización económica de España, sino también su contribución al sostenimiento del sistema político imperante a través de su integración en 
los partidos dinásticos y a su identificación con las premisas de su acción de gobierno.

Este grupo social, producto de la convergencia -materializada con frecuencia en forma de matrimonios- de comerciantes bilbaínos y notables rurales así como de acaudalados repatriados de América, dispuso de capital e iniciativa empresarial suficientes como para aprovechar las oportunidades que le brindaron la explotación en gran escala del mineral de hierro de Somorrostro y la generalización del procedimiento Bessemer para la obtención de lingote de acero. Nuevas iniciativas en sectores de la industria básica - siderometalurgia, construcción naval, química, etc-., en los transportes - marina mercante y ferrocarriles-, en los servicios -banca y seguros-, o en la producción y transporte de hidroelectricidad, elevaron su papel protagonista en la industrialización española y fortalecieron extraordinariamente su poder económico, muy concentrado en un número reducido de personas como consecuencia de la existencia de numerosos consejeros comunes en los órganos de dirección de sus empresas y de frecuentes lazos familiares entre ellos. El apoyo que este grupo prestó al sistema político de la Restauración, garantizado ya con el establecimiento de los Conciertos Económicos en 1878, tuvo su contrapartida en la opción proteccionista que adoptaron los gobiernos españoles a partir de 1891 reservando el mercado interior para la industria nacional, en la que los empresarios vizcainos tenían grandes intereses.

Como miembro destacado de este grupo, Sota reprodujo muchas de las características anotadas. Pero la dinámica de sus negocios y su propia definición política, contraria a la abolición foral y defensora de las tradiciones propias de Vizcaya, le mantuvieron alejado de sus representantes más influyentes y de la conducta que siguieron, llegando a sostener persistentes enfrentamientos con ellos, tanto en la esfera de la competencia económica como en el campo de la acción política. Su contribución a la modernización económica y política de la España de la Restauración no puede entenderse fuera de esta dialéctica.

\section{CONTRIBUCIÓN A LA MODERNIZACIÓN ECONÓMICA Y EMPRESARIAL DE ESPAÑA}

La primera característica que define la actividad empresarial de Sota, y una de las claves de la fortaleza del grupo de empresas que formó con su primo Eduardo Aznar, fue el elevado control y centralización de las 
decisiones del grupo a través de una sociedad matriz, asi como la dirección personalizada de ésta y de cada una de sus empresas. Sólo en contados casos accedieron Sota y Aznar a compartir colegiadamente la gestión y dirección de sus negocios con otros socios minoritarios. Lo cual guarda relación con la estructura de sus capitales sin apenas grandes accionistas, que no fuesen ellos mismos, y con un nutrido grupo de pequeñas participaciones en manos de empieados y allegados de diverso signo. Si la centralización de la estructura organizativa contribuyó a una gestión eficaz del conjunto de los negocios, especialmente en lo concerniente a la canalización de los recursos generados por el grupo hacia la reinversión, garantizando un crecimiento y expansión constantes, a la dirección personalizada no siempre pudo atribuirsele el éxito en los negocios puestos en marcha. Es más, cabe pensar que en algunos casos - los de mayor envergadura precisamente- se debió a ella en parte el que se emprendiesen en condiciones que conllevaban un elevado riesgo y que no se alcanzase el éxito perseguido. Tal es el caso, sobre todo, de la Compañía Siderúrgica del Mediterráneo.

La segunda característica guarda relación con la estructura productiva del grupo empresarial, definida por una integración vertical con la que intentaron abrirse paso en el comercio y transporte de mineral de hierro, primero, y eludir los perjuicios que ocasionaba el proteccionismo imperante al desenvolvimiento de sus empresas, después. Sota y Aznar iniciaron sus negocios comunes explotando minas de escasa importancia en Vizcaya, aunque sus principales intereses en el sector se localizaron en otros puntos de España, como Santander, Almería y Teruel. Durante la última década del siglo pasado adquirieron una flota de 25 buques mercantes con los que exportaron su producción de mineral de hierro a Gran Bretaña, e, incluso, se introdujeron en el transporte de carbón desde este país a Francia, España e Italia, asegurando con ello una actividad que hubiese encontrado muchas dificultades para su puesta en marcha de no haber dispuesto de los fletes de mineral propio.

Paralelamente al asentamiento de estos negocios, se impuso en España una política proteccionista, que afectó negativamente a los intereses del grupo al encarecérseles la adquisición de buques en el extranjero. Sota reaccionó frontalmente contra ella, y no encontró mejor manera de eludir sus efectos adversos que ampliando y consolidando la integración vertical del grupo. Asi, en 1900 fundó el astillero Euskalduna para reparar la flota vizcaina y atender su demanda de construcción de buques, al tiempo que concibió un proyecto siderúrgico propio con el fin de no tener que soportar los precios de monopolio de los productos siderúrgicos que se podian encontrar en el mercado nacional. Sus instalaciones se levan- 
tarian en Sagunto para aprovechar los minerales de Sierra Menera, conducidos hasta alli por un ferrocarril de más de 200 kilómetros, y reducirlos con la hulla británica traída en viaje de retorno por sus buques. Hasta 1917 no se constituyó la Compañia Siderúrgica del Mediterráneo, y sus instalaciones comenzaron a funcionar en 1923. Durante la Dictadura de Primo de Rivera obtuvo unos resultados más bien limitados, a pesar de que contó con la demanda estatal para ferrocarriles y obras públicas y de que se cartelizó con las tradicionales empresas del sector. Pero cuando aquella desapareció en 1930, su crisis se precipitó poniendo en evidencia una cuantiosa inversión y unas instalaciones con una capacidad de producción muy superior a la que podia absorber el mercado interior. La otra salida, el mercado internacional, había quedado descartada mucho antes por el aumento del proteccionismo en casi todos los países durante los años veinte, por la inestabilidad monetaria en los intercambios internacionales, y por el impulso dado por Mussolini a la industria básica italiana.

Mientras sus intereses económicos se circunscribieron a la exportación y al transporte marítimo de mineral de hierro, el proteccionismo resultó perjudicial para Sota, y contra él luchó denodadamente. Lo hizo, incluso, cuando ya funcionaba el astillero Euskalduna, para el que se encarecian en la frontera la maquinaria de propulsión y las materias primas importadas. No obstante, la crisis que afectó a la marina mercante vasca en los primeros años de este siglo, junto a la postura reacia del Gobierno a rebajar los aranceles y la de los siderúrgicos contraria a perder las ventajas que el sistema proteccionista les proporcionaba, motivaron que la recién constituida Asociación de Navieros de Bilbao, a cuyo frente se encontraba Sota, aceptase las premisas proteccionistas recibiendo a cambio primas a la navegación y a la construcción naval en 1909. El remedio sirvió para ayudar a salir de la crisis a la marina mercante y a los astilleros, pero no consiguió hacer competitivos internacionalmente ni a una ni a otros. Tampoco lo conseguiría la Dictadura, cuando Primo de Rivera concedió nuevamente primas con las que los armadores sólo paliaron los efectos de la crisis e inestabilidad de! comercio internacional en los resultados de sus empresas.

Aunque la aceptación de las primas no supuso reconocimiento de las excelencias del proteccionismo por parte de Sota - al contrario, siempre consideró que éstas no tenían sentido si se rebajaban o desaparecían los derechos arancelarios-, la puesta en marcha de los altos hornos de Sagunto y la necesidad de hacerse un hueco en el mercado nacional de productos siderúrgicos terminaron por convertirlo en un defensor de las medidas proteccionistas contenidas en el Arancel de 1922. Así es como 
todo su proyecto empresarial, concebido desde la integración vertical para afrontar debidamente la concurrencia nacional y extranjera, quedó atrapado en el sistema proteccionista vigente en España, buscando en adelante acomodo en él. Lo que prueba la gran capacidad de Sota para adaptarse a las circunstancias, es decir, su pragmatismo. Ni los años de la Dictadura ni los de la República, dominados éstos por una dura crisis económica, le dieron luego ocasión para desmarcarse de la protección estatal debido a los grandes intereses que tuvo que cuidar.

\section{CONTRIBUCIÓN A LA MODERNIZACIÓN POLITICA DE ESPAÑA}

En el aspecto político, Sota ofreció unas diferencias notables con respecto a los demás componentes de la "oligarquía vizcaína". De tradición familiar fuerista, aunque antes de 1876 lo eran la mayoría de los notables rurales pues tenían en las instituciones forales la garantía de su preponderancia sobre la colectividad, Sota fue de los intransigentes que se alinearon junto a Fidel de Sagarmínaga en el rechazo de la abolición foral decretada al concluir la última guerra carlista. En el seno de este grupo hizo sus primeras y más sobresalientes actuaciones en política, llegando a ser diputado provincial de Vizcaya entre 1888 y 1892.

Durante los años 90 fue conformando su propio grupo político con los elementos burgueses y liberales del campo fuerista, orientados doctrinalmente con su propio bagaje ideológico y la influencia del catalanismo de las Bases de Manresa, y, sobre todo, atraidos por la formulación nacionalista de los hermanos Arana Goiri, con los que mantuvieron una dialéctica de atracción-repulsión, preludio de un futuro proyecto político común.

Aunque los planteamientos político-doctrinales de ambos grupos diferían en cuestiones esenciales, siendo el sustrato racista y el independentismo del nacionalismo aranista lo menos aceptable para el fuerismo de Sota, un acontecimiento ajeno a ellos aceleró con confluencia en el Partido Nacionalista Vasco. El desastre de 1898 puso de manifiesto la crisis del sistema político de la Restauración y sus limitaciones para vertebrar un Estado moderno capaz de atender e impulsar las demandas de los grupos regionales que la industrialización estaba configurando. En Vizcaya, esta crisis tuvo la particularidad de poner en evidencia a los grandes empresarios dinásticos, dueños de la representación política de 
Ramón de la Sota: La contribución de un empresario vasco ...

la provincia, y la ayuda que sus negocios estaban recibiendo del sistema proteccionista vigente, dejando al descubierto su alianza con un sistema político obsoleto.

Tanto la confrontación que Sota mantenía con ellos sobre este asunto, como la necesidad de conformar un partido político moderno capaz de integrar poco a poco a la mayoría del cuerpo social de Vizcaya y del resto de las provincias vascas con objeto de arrebatar la hegemonía política regional a los dinásticos y de alcanzar la recuperación foral, le llevó a integrarse en 1899 en el partido de Arana, que salió así notablemente reforzado en medios materiales y en cuadros dirigentes. La unión no fue sencilla. En realidad, eran dos corrientes con visiones diferentes del proyecto nacionalista: moderada, laica y autonomista la de los seguidores de Sota, y radical, integrista e independentista la de los aranistas. De ahi que los enfrentamientos prosiguiesen durante las tres primeras décadas de este siglo, aunque ahora en el seno del Partido Nacionalista Vasco. Los seguidores de la corriente que Sota representaba trabajaron en todo momento por configurar un partido democrático, moderno, práctico, capaz de gobernar en los niveles municipal y provincial (Ayuntamientos y Diputaciones vascas), y por controlar las riendas de su dirección, originándose numerosos conflictos internos. Para esta corriente, el punto de referencia, tanto desde el punto de vista ideológico como de la misma práctica política, era el catalanismo de la Lliga y el pragmatismo de su líder, Cambó.

Después del fracaso de Maura durante su Gobierno Largo para atraerse al catalanismo y al sector sotista del nacionalismo vasco, tuvo que ser una nueva circunstancia excepcional la que crease las condiciones para que estas dos corrientes políticas, representantes de una concepción modernizadora y descentralizada del Estado, alcanzasen su máxima pujanza y el momento de mayor influencia ante las instituciones estatales. La Primera Guerra Mundial favoreció una gran acumulación de capital, especialmente entre los empresarios vascos y catalanes, que se vieron extraordinariamente fortalecidos al tiempo que el Estado de la Restauración entraba en su ocaso definitivo durante la crisis de 1917. Los seguidores políticos de Sota, que se habían hecho con el control del Partido Nacionalista Vasco, alcanzaron entre 1917 y 1920 la hegemonía política provincial gobernando la Diputación de Vizcaya y movilizando a la opinión pública regional en defensa de un Estatuto de Autonomía para el País Vasco, de forma semejante a como lo hicieron Cambó y los suyos para Cataluña. La presión fue grande. Pero la oportunidad de vertebrar un Estado descentralizado, que garantizase su modernización, se perdió una vez más, produciendo muchas de las frustaciones que luego aflora- 
ron durante la Segunda República. Fueron estos años, pues, los de mayor pujanza del nacionalismo moderado que representaba el sector sotista. Pero su propuesta política en favor de una alternativa modernizadora del Estado en sintonía con los países más avanzados de la Europa Occidental, como Inglaterra y Francia, no encontró cabida entre los obsoletos principios del sistema político de la Restauración. El pragmatismo que Sota adoptó en su relación con el Estado durante la Dictadura de Primo de Rivera guardaba relación tanto con esta evidencia como con los grandes intereses económicos que tenía que defender.

En síntesis, puede decirse que el proyecto global de Sota, tanto empresarial como político, no encontró el escenario ni los cauces apropiados para su desenvolvimiento en la configuración del mercado y del sistema político vigentes durante la Restauración. Ahora bien, es preciso señalar que mientras su proyecto empresarial, concebido entre otras cosas para eludir los costes del proteccionismo vigente, quedó inmerso en él después de la Primera Guerra Mundial, beneficiándose consiguientemente de sus ventajas, su proyecto político sólo encontró el marco adecuado para manifestarse y alcanzar sus objetivos durante la Segunda República. No en vano, el nacionalismo vasco moderado obtuvo el Estatuto de Autonomía para el País Vasco en plena vigencia de las instituciones republicanas, aunque ya en situación de guerra civil abierta. 